\title{
Penerapan Metode Average Based Fuzzy Time Series Lee Untuk Peramalan Harga Emas di PT. X
}

\section{Nurul Hani Pajriati*}

Prodi Matematika, Fakultas Matematika dan Ilmu Pengetahuan Alam, Universitas Islam Bandung, Indonesia.

*nurulhanifajriati13@gmail.com

\begin{abstract}
Gold is one of investment that can provide attractive benefits in the future. One of the advantages of investing in gold is that the value of its assets is not significantly eroded by inflation. Although gold prices tend to be stable, investment risks remain. Therefore we need a method that can help to find out the prediction of the gold price at the time that will be the basis for making a decision. One of them is by using Fuzzy Time Series Lee's method. Fuzzy time series lee's method is a combination of fuzzy logic concepts with time series forecasting that can solve forecasting problems. This article discusses gold price forecasting at PT. Pegadaian from September 1, 2020 to February 28, 2021. From the results of the research conducted, it is known that the prediction of gold price data using average based fuzzy time series lee results in a gold price of Rp. 872,500 and has an error rate based on the MAPE (Mean Absolute Percentage Error) value of $0.4364 \%$. These results include very good criteria.
\end{abstract}

Keywords: Fuzzy Time Series Lee (FTS), Mean Absolute Percentage Error (MAPE)

\begin{abstract}
Abstrak. Emas merupakan salah satu bentuk investasi yang dapat membawa keuntungan menarik di masa yang akan datang. Salah satu keuntungan dari berinvestasi emas adalah nilai asetnya yang tidak tergerus inflasi secara signifikan. Meskipun harga emas cenderung stabil, tetapi resiko investasi emas tetap ada. Maka dari itu perlu suatu metode yang dapat membantu untuk mengetahui prediksi harga emas diwaktu yang akan sebagai dasar untuk membuat suatu keputusan. Salah satunya dengan menggunakan metode Fuzzy Time Series Lee. Metode fuzzy time series lee merupakan gabungan konsep logika fuzzy dengan peramalan time series yang dapat menyelesaikan permasalahan suatu peramalan. Artikel ini mendiskusikan tentang peramalan harga emas di PT. Pegadaian dari tanggal 1 September 2020 sampai tanggal 28 Februari 2021. Dari hasil penelitian yang dilakukan, diketahui bahwa prediksi data harga emas menggunakan average based fuzzy time series lee menghasilkan harga emas sebesar Rp. 872.500 dan memiliki tingkat kesalahan (error) berdasarkan nilai MAPE (Mean Absolute Percentage Error) sebesar 0,4364\%. Hasil tersebut termasuk kriteria sangat baik.
\end{abstract}

Kata Kunci : Fuzzy Time Series Lee (FTS), Mean Absolute Percentage Error (MAPE) 


\section{A. Pendahuluan}

Di masa pandemi covid-19 ini, kondisi ekonomi di Indonesia nampak memprihatinkan. Salah satu dampak dari pandemi covid-19 yaitu ketidakpastian ekonomi. Kondisi ekonomi yang tidak stabil ini membuat banyak orang lebih berhati-hati dalam berinvestasi dan cenderung memilih investasi yang dianggap aman dan memiliki resiko yang minimum. Salah satu investasi yang dianggap aman di saat kondisi ekonomi tidak stabil seperti sekarang ini adalah investasi emas. Karena investasi emas memiliki risiko yang relatif rendah dan merupakan salah satu bentuk investasi riil yang dapat membawa keuntungan menarik di masa yang akan datang. Salah satu keuntungan terbaik dari berinvestasi emas adalah nilai asetnya yang tidak tergerus inflasi secara signifikan. Selain itu, emas memiliki nilai yang cenderung stabil dan memiliki likuiditas tinggi (mudah dicairkan) dibandingkan dengan investasi lain seperti saham dan properti. Jika dahulu investasi emas terbatas pada kepemilikan fisik seperti emas perhiasan dan emas batangan, kini investasi emas bisa dilakukan secara nonfisik lewat produk tabungan emas. Tabungan Emas adalah layanan pembelian dan penjualan emas dalam bentuk invetasi logam mulia melalui fasilitas seperti menabung.

Meskipun harga emas cenderung stabil dan selalu memiliki trend yang menaik, tetapi resiko investasi emas tetap ada. Hal ini bisa terjadi karena harga emas di pasaran bisa naik dan turun tergantung kondisi dan permintaan. Maka dari itu perlu adanya sistem yang dapat membantu untuk mengetahui prediksi harga emas diwaktu yang akan datang sebagai dasar bagi para investor dalam pengambilan keputusan.

Logika fuzzy sebagai salah satu komponen dari soft computing, telah banyak diaplikasikan di berbagai bidang kehidupan. Salah satu aplikasi terpentingnya adalah untuk membantu manusia dalam melakukan pengambilan keputusan[1]. Penelitian ini menggunakan logika fuzzy untuk menganalisis data time series harga emas dan membentuknya menjadi suatu model peramalan. Alasan digunakannya logika fuzzy dalam peramalan harga emas adalah karena teori himpunan fuzzy menyediakan kerangka teori yang sesuai dan tepat dalam perhitungan pola data dan dapat memberikan toleransi terhadap suatu ketidakpastian. Logika fuzzy menjadi penghubung antara data kuantitatif (numeris) dengan data kualitatif (linguistik).

Data harga emas merupakan data time series yang mengandung nilai linguistik. Variabel fuzzy pada data harga emas adalah persentase perubahan data harga emas dari waktu ke waktu. Nilai linguistik pada perubahan data harga emas adalah pengidentifikasian kestabilan harga emas misalnya "mahal", "sangat mahal", "agak mahal","murah", dan lain, lain[2]. Nilai linguistik tersebut tidak dapat diselesaikan menggunakan metode time series biasa. Sehingga digunakanlah metode fuzzy time series, dimana metode fuzzy time series tersebut merupakan gabungan konsep logika fuzzy dengan peramalan time series yang dapat menyelesaikan permasalahan pada peramalan menggunakan data harga emas.

Fuzzy time series adalah konsep baru yang diusulkan oleh Song dan Chissom berdasarkan konsep fuzzy set sebagai perhitungannya. Fuzzy time series merupakan metode peralamalan yang mana data historisnya dibentuk ke dalam nilai-nilai linguistik. Metode ini dapat menangkap pola dari data yang telah lalu kemudian digunakan untuk memproyeksikan ke masa yang akan datang [3]. Kelebihan metode fuzzy time series tidak membutuhkan asumsi kestasioneran seperti pada metode peramalan konvensional [4]. Dalam metode fuzzy time series terdapat berbagai model yaitu model Song, Chissom, Chen dan Lee[5].

Fuzzy time series lee adalah salah satu model dari metode fuzzy time series yang merupakan perkembangan dari model Song dan Chissom, Cheng, dan Chen dalam meramalkan suatu nilai di masa yang akan datang (Qiu dkk, 2011). Model ini memiliki langkah-langkah untuk peramalan yang hampir sama dengan FTS lainnya. Hanya saja, FTS Lee memiliki perbedaan dengan FTS konvensional yang terletak pada pembentukan Fuzzy Logical Relationship Group (FLRG).

Artikel ini akan mendiskusikan tentang peramalan harga emas di PT. X dengan metode average based fuzzy time series lee dan mengukur tingkat kesalahan dari hasil peramalan berdasarkan nilai Mean Absolute Percentage Error (MAPE). 


\section{B. Metodologi}

\section{Penentuan Interval Berbasis rata-rata}

Panjang interval sangat berpengaruh terhadap pembentukkan fuzzy relationship, dan fuzzy relationship juga memengaruhi hasil perhitugan peramalan. Maka untuk mendapatkan hasil fuzzy relationship yang tepat, penentuan panjang intervalnya pun harus sesuai. Salah satu metode yang efektif untuk menentukan panjang interval yaitu dengan menggunakan metode average based atau metode berbasis rata-rata.

Langkah-langkah dalam melakukan penentuan interval menggunakan metode average based length adalah sebagai berikut [6]:

1. Menghitung rata-rata selisih absolut pada setiap data

2. Menentukan panjang interval, nilai yang telah diperoleh dari langkah satu dibagi 2 (dua)

3. Mentukan nilai basis untuk panjang interval berdasarkan tabel basis intrerval pada tabel. 1

4. Menghitung jumlah interval.

Tabel 1. Basis Interval

\begin{tabular}{|c|c|}
\hline Jangkauan & Basis \\
\hline $0,1-1,0$ & 0,1 \\
\hline $1,1-10$ & 1 \\
\hline $11-100$ & 10 \\
\hline $101-1000$ & 100 \\
\hline $1001-10000$ & 1000 \\
\hline
\end{tabular}

\section{Langkah-langkah fuzzy time series lee}

5. Menentukan himpunan semesta pembicara $\mathrm{U}$ (Univers of discourse)

6. Menentukan jumlah interval fuzzy

7. Mendefinisikan himpunan fuzzy $A_{i}$ dan melakukan fuzzifikasi.

8. Menetukan Fuzzy Logical Relationship (FLR)

9. Membentuk Fuzzy Logical Relationship Group (FLRG).

10. Defuzzifikasi.

\section{Akurasi Metode Peramalan}

Mean Absolut Percentage Error (MAPE) adalah persentase kesalahan rata-rata secara multak (absolute). Pengertian MAPE adalah Pengukuran statistik tentang akurasi perkiraan (prediksi) pada metode peramalan. Nilai MAPE memberikan informasi seberapa besar kesalahan peramalan dibandingkan dengan nilai sebenarnya dari periode tersebut. Semakin kecil nilai presentasi kesalahan (percentage error) pada MAPE maka semakin akurat hasil peramalan tersebut.

MAPE dirumuskan sebagai berikut :

$$
M A P E=\frac{\sum_{t=1}^{n}\left|\frac{D_{t}-Y_{t}}{D_{t}}\right|}{n} * 100 \%
$$

\section{Hasil Penelitian dan Diskusi}

Data yang digunakan dalam penelitian ini adalah data harga emas harian PT. X dari tanggal 1 September 2020 sampai dengan tanggal 28 Februari 2021 yang berjumlah sebanyak 179 data. Penelitian ini bertujuan untuk memprediksi harga emas di PT X periode ke depan pada tanggal 1 Maret 2021 Menggunakan Metode Average Based Fuzzy Time Series Lee. Setelah itu, tingkat kesalahan hasil prediksi akan dihitung berdasarkan nilai MAPE. Pengolahan data dalam penelitian ini menggunakan bantuan software microsoft excel. 
Data yang digunakan dalam penelitian ini adalah data sekunder, dimana peneliti tidak terjun kelapangan langsung untuk memperoleh data, melainkan diperoleh dari situs resmi Pegadaian https://www.pegadaian.co.id/produk/ tabungan-emas [7]. Adapun data harga emas harian PT. X dari tanggal 1 September 2020 sampai dengan tanggal 28 Februari 2021 dapat dilihat pada tabel berikut:

Tabel 2. Data Harga Emas

\begin{tabular}{|c|c|c|c|c|c|}
\hline No & Tanggal & $\begin{array}{c}\text { Harga } \\
\text { Emas }\end{array}$ & No & Tanggal & $\begin{array}{c}\text { Harga } \\
\text { Emas }\end{array}$ \\
\hline 1 & 01 September 2020 & 974000.00 & 7 & 07 September 2020 & 972000.00 \\
\hline 2 & 02 September 2020 & 978000.00 & 8 & 08 September 2020 & 966000.00 \\
\hline 3 & 03 September 2020 & 976000.00 & 9 & 09 September 2020 & 966000.00 \\
\hline 4 & 04 September 2020 & 973000.00 & 10 & 10 September 2020 & 974000.00 \\
\hline 5 & 05 September 2020 & 973000.00 & $\vdots$ & $\vdots$ & $\vdots$ \\
\hline 6 & 06 September 2020 & 973000.00 & 179 & 28 Februari 2021 & 871.000 \\
\hline
\end{tabular}

Dari data pada tabel 2, diperoleh harga emas tertinggi terjadi pada tanggal 15 September 2020 sebesar Rp. 983.000,00 dan harga emas terendah terjadi pada tanggal 18-20 Februari 2021 sebesar Rp. 866.000,00. Sedangkan rata-ratanya adalah Rp. 920.513,97.

\section{Hasil Pembahasan}

Berikut langkah-langkah peramalan harga emas PT. Pegadaian pada tanggal 1 September 2020 sampai dengan tanggal 28 Februari 2021.

Langkah pertama : Menentukan himpunan semesta $U$, dengan formula :

$$
U=\left[D_{\min }-Z_{1}, D_{\max }+Z_{2}\right]
$$

Di mana $Z_{1}$ dan $Z_{2}$ merupakan sembarang bilangan positif yang ditentukan oleh peneliti. Maka diperoleh:

$$
\begin{aligned}
U & =[866.000-500,983.000+500] \\
& =[865.500,983.500]
\end{aligned}
$$

Langkah kedua : Menentukan jumlah interval fuzzy menggunakan metode average based (interval berbasis rata-rata).

1. Menghitung rata-rata selisih absolut pada setiap data. Dengan rumus sebagai berikut:

$$
\begin{aligned}
& S_{m}=\left|D_{t+1}-D_{t}\right| \\
& \text { mean }=\frac{\sum_{t=1}^{n-1}\left|D_{t+1}-D_{t}\right|}{n-1}
\end{aligned}
$$

Selisih absolut dapat dilihat pada tabel 3 : 
Tabel 3. Selisih Absolut

\begin{tabular}{|c|c|c|c|}
\hline No & Tanggal & Harga Emas & Selisih Absolut \\
\hline 1 & 1 September 2020 & 974.000 & 4000 \\
\hline 2 & 2 September 2020 & 978.000 & 2000 \\
\hline 3 & 3 September 2020 & 976.000 & 3000 \\
\hline 4 & 4 September 2020 & 973.000 & 0 \\
\hline 5 & 5 September 2020 & 973.000 & 0 \\
\hline 6 & 6 September 2020 & 973.000 & 1000 \\
\hline 7 & 7 September 2020 & 972.000 & 6000 \\
\hline 8 & 8 September 2020 & 966.000 & 0 \\
\hline 9 & 9 September 2020 & 966.000 & 8000 \\
\hline 10 & 10 September 2020 & 974.000 & 4000 \\
\hline$\vdots$ & $\vdots$ & $\vdots$ & $\vdots$ \\
\hline 178 & 27 Oktober 2021 & 871.000 & 0 \\
\hline 179 & 28 Oktober 2021 & 701.000 \\
\hline \multicolumn{3}{|c|}{ Jumlah }
\end{tabular}

Diperoleh rata-rata selisih absolute sebagai berikut :

$$
\begin{aligned}
\text { mean } & =\frac{701.000}{178} \\
& =3938,202
\end{aligned}
$$

2. Menentukan panjang interval dengan rumus sebagai berikut:

$$
\begin{aligned}
K & =\frac{\text { mean }}{2} \\
& =\frac{3938,202}{2} \\
& =1969,101
\end{aligned}
$$

3. Berdasarkan hasil perhitungan pada bagian dua, diperoleh nilai basis interval yaitu 1969,101, nilai tersebut berdasarkan tabel 3 termasuk kedalam basis interval 1000. Maka nilai 1969,101 dibulatkan menjadi 2000. Sehingga diperoleh panjang interval sebesar 2000.

4. Selanjutnya menghitung jumlah interval dengan persamaan (2.5) :

$$
\begin{aligned}
n & =\frac{D_{\max }+Z_{2}-D_{\min }-Z_{1}}{K} \\
n & =\frac{983.000+500-866.000-500}{2000} \\
& =58,5 \\
& \approx 59
\end{aligned}
$$

Selanjutya membagi himpunan $U=[865.500,983.500]$ kedalam 59 interval dengan panjang interval yang sama yaitu 2000.

$$
\begin{aligned}
& u_{1}=[865.500,867.500) \\
& u_{2}=[867.500,869.500) \\
& u_{3}=[869.500,871.500) \\
& \vdots \\
& u_{59}=[981.500,983.500)
\end{aligned}
$$


Berdasarkan pembagian tersebut, himpunan fuzzy dan nilai tengah $u_{i}(\mathrm{i}=1,2, \ldots, 59)$ dapat dilihat pada tabel 4 :

Tabel 4. Himpunan Fuzzy dan Nilai Tengah

\begin{tabular}{|c|c|c|c|}
\hline \multirow{2}{*}{ Interval } & \multicolumn{2}{|c|}{ Himpunan fuzzy $\left(u_{i}\right)$} & \multirow{2}{*}{ Nilai tengah $\left(m_{i}\right)$} \\
\cline { 2 - 3 } & Batas bawah & Batas atas & 866.500 \\
\hline$u_{1}$ & 865.500 & 867.500 & 868.500 \\
\hline$u_{2}$ & 867.500 & 869.500 & 870.500 \\
\hline$u_{3}$ & 869.500 & 871.500 & 872.500 \\
\hline$u_{4}$ & 871.500 & 873.500 & 874.500 \\
\hline$u_{5}$ & 873.500 & 875.500 & 876.500 \\
\hline$u_{6}$ & 875.500 & 877.500 & 878.500 \\
\hline$u_{7}$ & 877.500 & 879.500 & 880.500 \\
\hline$u_{8}$ & 879.500 & 881.500 & 882.500 \\
\hline$u_{9}$ & 881.500 & 883.500 & 884.500 \\
\hline$u_{10}$ & 883.500 & 885.500 & $\vdots$ \\
\hline$\vdots$ & $\vdots$ & $\vdots$ & 982.500 \\
\hline$u_{59}$ & 981.500 & 983.500 & \\
\hline
\end{tabular}

Langkah ketiga : mendefinisikan himpunan fuzzy $A_{i}$ dan melakukan fuzzifikasi.

Berikut pendefinisian derajat keanggotaan himpunan fuzzy terhadap $A_{i}$ :

$$
\begin{gathered}
A_{1}=1 / u_{1}+0.5 / u_{2}+0 / u_{3}+\cdots+0 / u_{59} \\
A_{2}=0.5 / u_{1}+1 / u_{2}+0.5 / u_{3}+\cdots+0 / u_{59} \\
A_{3}=0 / u_{1}+0.5 / u_{2}+1 / u_{3}+\cdots+0 / u_{59} \\
\vdots \quad \vdots \quad \vdots \quad \vdots \quad \cdots \quad \vdots \\
A_{59}=0 / u_{1}+0 / u_{2}+0 / u_{3}+\cdots+1 / u_{59}
\end{gathered}
$$

Simbol "/" menyatakan derajat keanggotaan $u_{i}$ terhadap $A_{i}(i=1,2,3, \ldots, 59)$ dengan nilai $0,0.5$, dan 1 . Sedangkan tanda (+) tidak melambangkan operasi penjumlahan, melainkan melambangkan keseluruhan unsur $u_{i}$. Misal $A_{1}$ merupakan hasil fuzzifikasi yang diperoleh dari pendefinisian derajat keanggotaan himpunan fuzzy $u_{i}$ terhadap $A_{1}$.

Diperoleh fuzzifikasi data harga emas di PT. X sebagai berikut:

Tabel 5. Fuzzifikasi

\begin{tabular}{|c|c|c|c|}
\hline No & Tanggal & Harga Emas & Fuzzifikasi \\
\hline 1 & 1 September 2020 & 974000.00 & $A_{55}$ \\
\hline 2 & 2 September 2020 & 978000.00 & $A_{57}$ \\
\hline 3 & 3 September 2020 & 976000.00 & $A_{56}$ \\
\hline 4 & 4 September 2020 & 973000.00 & $A_{54}$ \\
\hline 5 & 5 September 2020 & 973000.00 & $A_{54}$ \\
\hline 6 & 6 September 2020 & 973000.00 & $A_{54}$ \\
\hline 7 & 7 September 2020 & 972000.00 & $A_{54}$ \\
\hline 8 & 8 September 2020 & 966000.00 & $A_{51}$ \\
\hline 9 & 9 September 2020 & 966000.00 & $A_{51}$ \\
\hline 10 & 10 September 2020 & 974000.00 & $A_{55}$ \\
\hline$\vdots$ & $\vdots$ & $\vdots$ & $\vdots$ \\
\hline 179 & 28 Februari 2021 & 871000.00 & $A_{3}$ \\
\hline
\end{tabular}


Langkah keempat : Manetukan Fuzzy Logical Relationship (FLR). Fuzzy Logical Relationship (FLR) dilakukan dengan cara merelasikan $A_{i} \rightarrow A_{i+1}$. Maka diperoleh FLR sebagai berikut :

Tabel 6. Fuzzy Logical Relationship (FLR)

\begin{tabular}{|c|c|c|c|}
\hline No & Tanggal & Harga Emas & FLR \\
\hline 1 & 01 September 2020 & 974000.00 & - \\
\hline 2 & 02 September 2020 & 978000.00 & $A_{55} \rightarrow A_{57}$ \\
\hline 3 & 03 September 2020 & 976000.00 & $A_{57} \rightarrow A_{56}$ \\
\hline 4 & 04 September 2020 & 973000.00 & $A_{56} \rightarrow A_{54}$ \\
\hline 5 & 05 September 2020 & 973000.00 & $A_{54} \rightarrow A_{54}$ \\
\hline 6 & 06 September 2020 & 973000.00 & $A_{54} \rightarrow A_{54}$ \\
\hline 7 & 07 September 2020 & 972000.00 & $A_{54} \rightarrow A_{54}$ \\
\hline 8 & 08 September 2020 & 966000.00 & $A_{54} \rightarrow A_{51}$ \\
\hline 9 & 09 September 2020 & 966000.00 & $A_{51} \rightarrow A_{51}$ \\
\hline 10 & 10 September 2020 & 974000.00 & $A_{51} \rightarrow A_{55}$ \\
\hline$\vdots$ & $\vdots$ & $\vdots$ & $\vdots$ \\
\hline 179 & 28 February 2021 & 871000.00 & $A_{3} \rightarrow A_{3}$ \\
\hline
\end{tabular}

Langkah kelima membentuk Fuzzy Logical Relationship Group (FLRG). FLRG adalah mengelompokkan fuzzyfikasi yang memiliki satu current state yang sama menjadi satu grup. Hasil FLRG dapat dilihat pada tabel berikut :

Tabel 7. Fuzzy Logical Relationship Group (FLRG)

\begin{tabular}{|c|l|}
\hline Grup & \multicolumn{1}{|c|}{ FLRG } \\
\hline 1 & $A_{1} \rightarrow A_{1}, A_{1}, A_{3}$ \\
\hline 2 & $A_{3} \rightarrow A_{3}, A_{3}, A_{6}$ \\
\hline 3 & $A_{4} \rightarrow A_{8}$ \\
\hline 4 & $A_{5} \rightarrow A_{1}, A_{5}$ \\
\hline 5 & $A_{6} \rightarrow A_{3}, A_{5}, A_{6}, A_{6}, A_{6}, A_{7}$ \\
\hline 6 & $A_{7} \rightarrow A_{4}, A_{6}, A_{9}$ \\
\hline 7 & $A_{8} \rightarrow A_{8}, A_{8}, A_{9}, A_{10}, A_{12}$ \\
\hline 8 & $A_{9} \rightarrow A_{6}, A_{7}, A_{10}, A_{23}$ \\
\hline 9 & $A_{10} \rightarrow A_{7}, A_{8}, A_{9}, A_{12}$ \\
\hline 10 & $A_{11} \rightarrow A_{10}, A_{11}, A_{11}, A_{11}, A_{11}$ \\
\hline$\vdots$ & $\vdots$ \\
\hline 45 & $A_{59} \rightarrow A_{58}$ \\
\hline
\end{tabular}

Langkah keenam : Defuzzifikasi. Pada tahap ini, fuzzy output akan diubah menjadi crips value berdasarkan fungsi keanggotaan dengan tujuan untuk melakukan perhitungan hasil prediksi. Proses perhitungan defuzzyfikasi model Lee mengikuti persamaan (2.8), (2.9) dan (2.10). Maka diperoleh hasil perhitungan defuzzyfikasi model Lee sebagai berikut : 
Tabel 8. Defuzzifikasi

\begin{tabular}{|c|c|c|c|}
\hline Grup & $\begin{array}{c}\text { Current } \\
\text { State }\end{array}$ & \multicolumn{1}{|c|}{ FLRG } & Peramalan \\
\hline 1 & $A_{1}$ & $A_{1}, A_{1}, A_{3}$ & $A_{1}=867.833,33$ \\
\hline 2 & $A_{3}$ & $A_{3}, A_{3}, A_{6}$ & $A_{3}=872.500$ \\
\hline 3 & $A_{4}$ & $A_{8}$ & $A_{4}=880.500$ \\
\hline 4 & $A_{5}$ & $A_{1}, A_{5}$ & $A_{5}=870.500$ \\
\hline 5 & $A_{6}$ & $A_{3}, A_{5}, A_{6}, A_{6}, A_{6}, A_{7}$ & $A_{6}=875.500$ \\
\hline 6 & $A_{7}$ & $A_{4}, A_{6}, A_{9}$ & $A_{7}=877.166,67$ \\
\hline 7 & $A_{8}$ & $A_{8}, A_{8}, A_{9}, A_{10}, A_{12}$ & $A_{8}=883.300$ \\
\hline 8 & $A_{9}$ & $A_{6}, A_{7}, A_{10}, A_{23}$ & $A_{9}=887.500$ \\
\hline 9 & $A_{10}$ & $A_{7}, A_{8}, A_{9}, A_{12}$ & $A_{10}=882.500$ \\
\hline 10 & $A_{11}$ & $A_{10}, A_{11}, A_{11}, A_{11}, A_{11}$ & $A_{11}=886.100$ \\
\hline$\vdots$ & $\vdots$ & $\vdots$ & $A_{59}=980.500$ \\
\hline 46 & $A_{59}$ & $A_{58}$ & \\
\hline
\end{tabular}

Hasil peramalan harga emas di PT. Pegadaian dari tanggal 1 September 2020 sampai tanggal 28 Februari 2021 dapat dilihat pada tabel berikut :

Tabel 9. Hasil Peramalan

\begin{tabular}{|c|c|c|c|c|}
\hline No & Tanggal & Harga Emas & FLR & Peramalan \\
\hline 1 & 01 September 2020 & 974000.00 & - & - \\
\hline 2 & 02 September 2020 & 978000.00 & $A_{55} \rightarrow A_{57}$ & 978.500 \\
\hline 3 & 03 September 2020 & 976000.00 & $A_{57} \rightarrow A_{56}$ & 978.100 \\
\hline 4 & 04 September 2020 & 973000.00 & $A_{56} \rightarrow A_{54}$ & 973.500 \\
\hline 5 & 05 September 2020 & 973000.00 & $A_{54} \rightarrow A_{54}$ & 971.000 \\
\hline 6 & 06 September 2020 & 973000.00 & $A_{54} \rightarrow A_{54}$ & 971.000 \\
\hline 7 & 07 September 2020 & 972000.00 & $A_{54} \rightarrow A_{54}$ & 971.000 \\
\hline 8 & 08 September 2020 & 966000.00 & $A_{54} \rightarrow A_{51}$ & 971.000 \\
\hline 9 & 09 September 2020 & 966000.00 & $A_{51} \rightarrow A_{51}$ & $967.166,67$ \\
\hline 10 & 10 September 2020 & 974000.00 & $A_{51} \rightarrow A_{55}$ & $967.166,67$ \\
\hline$\vdots$ & $\vdots$ & $\vdots$ & $\vdots$ & $\vdots$ \\
\hline 179 & 28 February 2021 & 871000.00 & $A_{3} \rightarrow A_{3}$ & 872.500 \\
\hline
\end{tabular}

\section{Akurasi Metode Peramalan}

Berikut adalah perhitungan nilai error menggunakan Mean Absolute Percentage Error (MAPE) berdasarkan persamaan (2.11) dan dapat dilihat pada tabel dibawah ini:

Tabel 10. Hasil MAPE

\begin{tabular}{|c|c|c|c|c|c|}
\hline No & Tanggal & $\begin{array}{c}\text { Harga } \\
\text { Emas }\end{array}$ & FLR & Peramalan & MAPE \\
\hline 1 & 01 September 2020 & 974.000 & - & - & - \\
\hline 2 & 02 September 2020 & 978.000 & $A_{55} \rightarrow A_{57}$ & 978.500 & 0,0005 \\
\hline 3 & 03 September 2020 & 976.000 & $A_{57} \rightarrow A_{56}$ & 978.100 & 0,0022 \\
\hline 4 & 04 September 2020 & 973.000 & $A_{56} \rightarrow A_{54}$ & 973.500 & 0,0005 \\
\hline 5 & 05 September 2020 & 973.000 & $A_{54} \rightarrow A_{54}$ & 971.000 & 0,0021 \\
\hline 6 & 06 September 2020 & 973.000 & $A_{54} \rightarrow A_{54}$ & 971.000 & 0,0021 \\
\hline 7 & 07 September 2020 & 972.000 & $A_{54} \rightarrow A_{54}$ & 971.000 & 0,0010 \\
\hline 8 & 08 September 2020 & 966.000 & $A_{54} \rightarrow A_{51}$ & 971.000 & 0,0052 \\
\hline
\end{tabular}




\begin{tabular}{|c|c|c|c|c|c|}
\hline 9 & 09 September 2020 & 966.000 & $A_{51} \rightarrow A_{51}$ & $967.166,67$ & 0,0012 \\
\hline 10 & 10 September 2020 & 974.000 & $A_{51} \rightarrow A_{55}$ & $967.166,67$ & 0,0070 \\
\hline$\vdots$ & $\vdots$ & $\vdots$ & $\vdots$ & $\vdots$ & $\vdots$ \\
\hline 179 & 28 February 2021 & 871.000 & $A_{3} \rightarrow A_{3}$ & 872.500 & 0,0017 \\
\hline \multicolumn{5}{|c|}{ Jumlah } & 0,7768 \\
\hline MAPE & $0,4364 \%$ \\
\hline
\end{tabular}

Dari Tabel 3.9, diperoleh nilai MAPE sebesar 0,4364\%. Maka peramalan dengan menggunakan metode fuzzy time series lee mempunyai kinerja sangat bagus dan memperoleh hasil peramalan sebesar 872.500 .

\section{Kesimpulan}

Berdasarkan hasil dan pembahasan yang telah dilakukan, kesimpulan yang diperoleh pada penelitian ini adalah hasil peramalan harga emas di PT. X pada tanggal 1 Maret 2021 dengan menggunakan metode Fuzzy Time Series Lee adalah sebesar Rp. 872.500 dengan MAPE $0,4364 \%$.

\section{Daftar Pustaka}

[1] S. Kusumadewi and H. Purnomo, Aplikasi Logika Fuzzy untuk Pendukung Keputusan, Yogyakarta: Graha Ilmu, 2010.

[2] S. M. Chen, "Forecasting enrollments based on fuzzy time series," Fuzzy Sets and System, 1996.

[3] S. Xihao and L. Yimin, "Average-based fuzzy time series models for forecasting shanghai compound index," World Journal of Modelling aand Simulation, 2008.

[4] L. A. Zadeh, "Fuzzy Sets", Information and control, 1965.

[5] L. C. Ramadhani, "Fuzzy Time Series Saxena-Easo Pada Peramalan Laju Inflasi Indonesia" Jurnal Ilmu Dasar, 2019.

[6] Q. Song and B. S. Chissom, "Forecasting enrollments based on fuzzy time series part I", Fuzzy sets and systems, 1993.

[7] "Pegadaian," Harga Emas Harian, 28 Februari 2021. [Online]. Available: https://www.pegadaian.co.id/harga. [Accessed 26 Mei 2021]. 